\title{
Burton Clark's The Higher Education System: Academic Organization in Cross-National Perspective
}

\author{
The Higher Education System: Academic Organization in Cross-National \\ Perspective, by Burton R. Clark, Berkeley and Los Angeles, University of California \\ Press, 1983
}

John Brennan*

Centre for Higher Education Research and Information, Open University, London and Milton Keynes, UK

\begin{abstract}
In The Higher Education System, Burton Clark provides a model for the organisational analysis of higher education institutions and systems. Central to the model are the concepts of knowledge, beliefs and authority. In particular, Clark examines how different interest groups both inside and outside the university shape and subvert the management of change. Within the university, Clark notes the tensions between the 'enterprise' and the 'discipline' and at the system level between the state authority, the market and the academic oligarchy. In considering the applicability of Clark's model to an understanding of today's higher education systems and institutions, one can note a weakening of boundaries both within higher education institutions and between them and other institutions of society. Arguably, there has been a lessening of the organisational distinctiveness of universities and an invasion by the language and ideas of the business world. The broadening of the social functions of modern higher education systems may be one of the reasons why academic authority seems to be subject to greater external challenge. Nevertheless, much of Clark's analytic model remains highly relevant to our understanding of higher education systems and institutions even if their empirical manifestations have changed over the intervening years. Clark's model shares much in common with a more recent analysis of the changing relationship between higher education and society conducted as part of a recent project of the European Science Foundation, although changes in emphasis and in authority relationships are also revealed.
\end{abstract}

Keywords: universities; academic organisation; disciplines; university management; higher education

In The Higher Education System, published in 1983, Burton Clark attempted to do four things simultaneously. The first was to apply perspectives and techniques from organisational sociology to the study of universities and the larger higher education systems of which they were a part. Secondly, while applying more general techniques of sociological analysis, he was also keen to acknowledge certain unique features of universities as social institutions. Thirdly, he drew on his substantial knowledge of a range of different national higher education systems to support and illustrate his analysis. And fourthly, he explicitly addressed normative issues concerning governance and decision-making in universities. On that final point, it is Clark's explicitness that is its distinctive feature. So much writing and analysis about universities is implicitly normative, reflecting and promoting values and interests of the author. But Clark was explicit about it, reflecting the fact/value dichotomies that were central to sociological ways of thinking at the time.

\footnotetext{
*Email: j.I.brennan@open.ac.uk 
Much has changed in the world and in universities since 1983. But then again, universities have been around a lot longer than 30 years and, for many authors, it is their longevity and traditions which are their defining features. The point is made powerfully right at the opening of The Higher Education System with a quotation from one of sociology's French founding fathers, Emile Durkheim:

It is rare to find an institution which is at once so uniform and so diverse; it is recognisable in all the guises which it takes, but in no one place is it identical with what it is in any other. This unity and diversity constitute the final proof of the extent to which the university was the spontaneous product of mediaeval life; for it is only living things which can in this way, while fully retaining their identity, bend and adapt themselves to a whole variety of circumstances and environments. (Emile Durkheim, The Evolution of Educational Thought, cited in Clark 1983, xiv)

One cannot but wonder whether, if writing a new edition of his book today, Clark would have found Durkheim's words quite so apposite to describe the forces driving university developments and organisation. Many of these were of course the focus of Clark's later work on Entrepreneurial Universities, exploring some of the consequences of 'academic capitalism' and the 'knowledge society' in broadly approving ways (Clark 1998).

It is, however, the analysis contained in the original book written in 1983 which is the focus of the present paper. I want to consider the extent to which its analytic framework remains serviceable in supporting our understanding of modern universities and higher education systems. I will also compare it briefly with recent work carried out by the European Science Foundation which also sought to locate the study of higher education systems within larger social science perspectives. And, finally, I would like to consider how much of Clark's normative framework we would wish to subscribe to today.

\section{A distinctive institution}

Some key words in Clark's 1983 analysis are 'disorder', 'uniqueness', 'differentiation' and 'interests' with especial emphasis on the latter: 'He who says academic organisation says interest groups' (Clark 1983, 10). And these terms are used in ways which have both analytic and normative force. There is a clear functionalist element to Clark's thinking here, with the implication that 'things need to be the way they are'.

Clark's starting point for his analysis, and the basis for his claims about 'distinctiveness', lie in the centrality of 'knowledge materials' and 'knowledge groups' to the organisational shape of universities. Along with UK authors, Maurice Kogan and Tony Becher (Becher 1989; Becher and Kogan 1980, 1992), Clark emphasised the centrality of the 'basic unit' of the subject-based university department to the delivery of the core functions of the university. In his analysis, Clark saw and welcomed the combination of weak boundaries between and strong autonomies within these basic units.

Central to the analysis of how work was organised in universities was the co-existence of the 'discipline' and the 'enterprise' as basic groupings bringing with them sources of values and authority. Much of the distinctiveness of the university as an organisation lay in the importance of disciplinary authority, summarised by Clark in three features: (i) the core membership unit in academic systems is discipline-centred; (ii) each disciplinary unit within the enterprise has selfevident and acclaimed primacy in a front-line task; (iii) the characteristics of core membership groups affect everything else of importance in the organisation (Clark 1983, 33-4). Clark notes at the time the differences that existed between the relative importance of discipline and enterprise authority in different national higher education systems. From a UK perspective, one can surely note a major shift in power from discipline to enterprise within most universities over the years since The Higher Education System was published, a shift partly caused by new managerial 
trends but also by developments in modes of knowledge organisation - more interdisciplinary courses for students and more 'mode 2' applied and interdisciplinary research. Indeed, an interesting trend to be observed in the UK and elsewhere is the organisational separation of research and teaching and the consequent diminution of disciplinary authority in the process.

Clark moves between system-level and institutional-level analyses and makes abundant use of typologies in the process. At the system level, he makes the distinction between horizontal and vertical forms of differentiation. The former is discussed in terms of the organisation of institutions into distinct sectors, distinguishing between (i) single public system: single sector (citing several Latin American and European Mediterranean countries as examples); (ii) single public system: multiple sectors (the most common form, citing Thailand, Iran and Poland as examples but finding the form pervasive more generally in communist societies, western democracies and Third World countries alike); (iii) multiple public systems: multiple sectors (with Australia, Canada, Great Britain, West Germany and Mexico all cited as examples); (iv) private and public systems: multiple sectors (with Japan and the US along with Chile, Peru, Columbia and Brazil all cited as examples). The reach of Clark's comparative perspectives is illustrated by the above. In his comments on the vertical differentiation of higher education systems in the early 1980s, Clark cites France and Great Britain as rather extreme examples with North American systems occupying the more middle ground and European countries such as Germany and Italy exhibiting relatively little status ranking. Nearly 30 years on, with global rankings obsessing at least the English-speaking university worlds, it is worth remembering that some national systems are still marked by relatively little status differences among institutions.

Turning to the institutional level, Clark proceeds to set out his organisational analysis of universities by reference to a series of questions, each of which is the subject of one of the book's chapters. The questions are: (i) How is work arranged? (ii) How are beliefs maintained? (iii) How is authority distributed? (iv) How are systems integrated? (v) How does change take place?

These are pretty central questions to our understanding of higher education and they are also pretty open ones empirically. In seeking to answer them, Clark warns of the dangers of adopting a 'hometown' view: 'Cross-national comparison is particularly advantageous in uncovering the unique features and unconscious assumptions that possess our vision when we study a single country, generally our own' (Clark 1983, 2).

The same sentiment could also be expressed about attempts to study our own universities. The familiarities of our everyday university worlds can get in the way of wider empiricallyinformed theorising about university systems (Brennan 2007).

In seeking answers to each of the five questions referred to above, Clark employs key concepts of knowledge, belief and authority. Relationships to knowledge are at the heart of the enterprises of the university's basic units which, along with beliefs, are central to the shaping of identities and relationships within the academic community. Adopting Tony Becher's notion of 'academic tribes', we can view the worlds of universities in terms of memberships of distinctive tribal cultures: 'a culture... some shared accounts and common beliefs that help define for participants who they are, what they are doing, why they are doing it, and whether they have been blessed or cursed' (Clark 1983, 72).

But it was in addressing questions of authority that Clark provided us with his most popular conceptual tool, the famous triangle of co-ordination! In looking at questions of authority, Clark's focus moved beyond the inner world of the individual higher education institution to consider the university's place in the larger worlds outside its doors. The 'triangle of co-ordination' had at its corners three sources of authority deriving from the state, the market and the academic oligarchy.

Looked at nearly 30 years on, both the positioning of individual countries and the overall distribution of countries within the triangle have changed, though the size of the movement of 


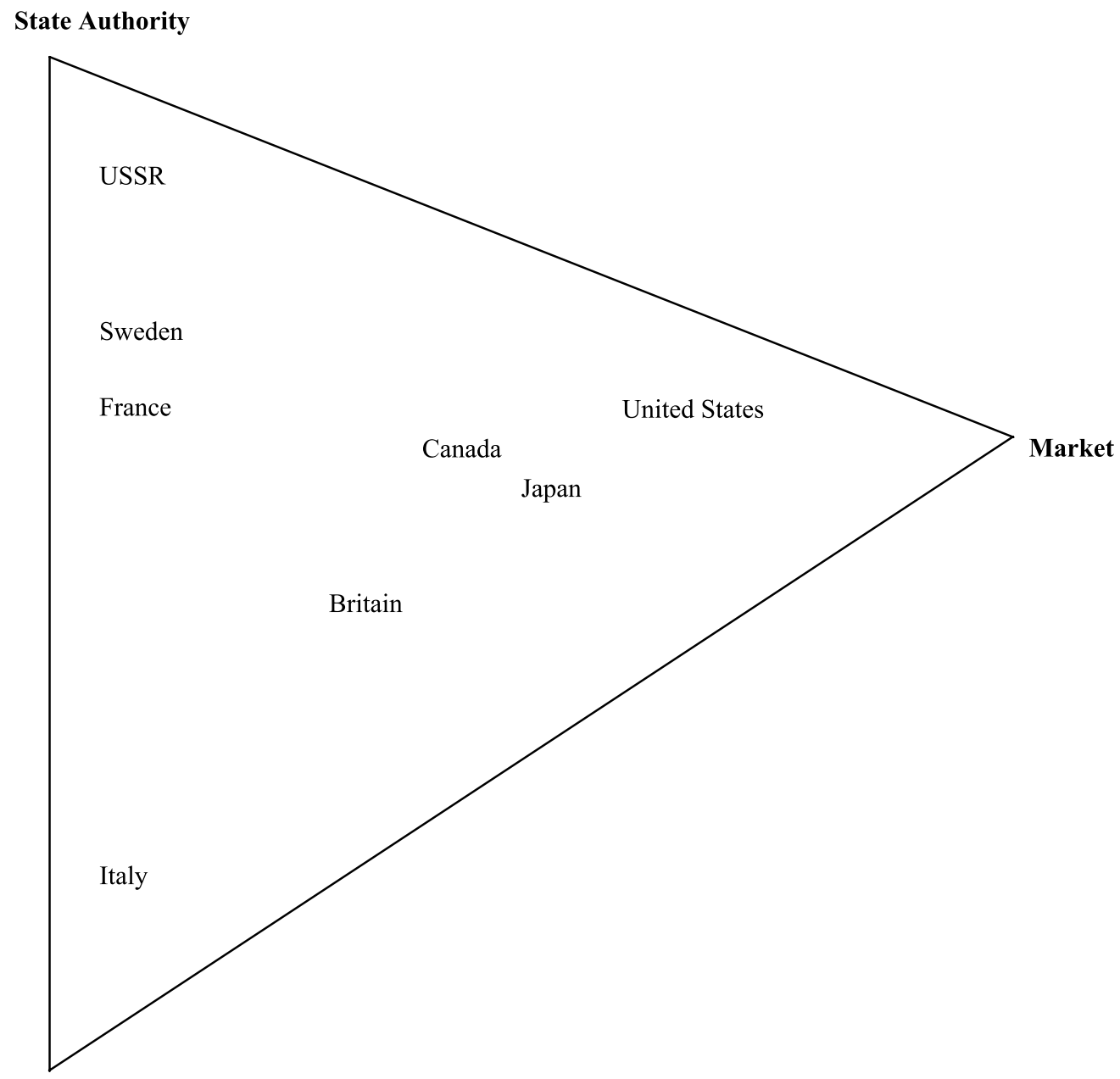

\section{Academic Oligarchy}

Figure I. The triangle of co-ordination (Clark 1983, 143).

individual countries within the walls of the triangle differ substantially. Arguably, Britain is one of the bigger movers heading away from the academic oligarchy in a zigzag fashion towards the corners of the state and the market. But that original positioning of countries in 1983 can serve to remind us of the force of traditions and history in attempting to understand the forces of power and authority in different jurisdictions today.

What, however, the triangle fails to do is to address the different ways in which power can be distributed at the academic oligarchy corner of the triangle, the differences between the managerial authority possessed by the institutional leaderships of universities based on the Anglo-Saxon model against the more distributed faculty authority models in combination with considerable professorial autonomy and authority of more Humboldtian models. The price of the latter could be greater state authority and of the former greater market authority or influence. It is arguably in the balancing of these different internal distributions of authority that most recent trends in university administration and governance lie. 
However, in the text of the book, Clark himself also distinguishes between different forms and levels of authority within the university. Thus, academic authority may be discipline-rooted with sub-types of personal rulership (professorial), collegial rulership (professorial), guild authority and professional authority all to be found. Within more enterprise-based authority, trustee authority (institutional) and bureaucratic authority (institutional) can be distinguished. And at the system level, bureaucratic authority (governmental), political authority and systemwide academic oligarchy can all be found. These elaborate typologies for understanding differences in the ways universities are organised at both system and institutional levels might be applied with value to enhancing our understanding of present-day diversities within and across higher education systems.

It is worth noting, however, that the two co-ordinating organisations of the academic oligarchy in the UK pointed to by Clark in 1983 - the University Grants Committee and the Council for National Academic Awards - have both long gone, the replacements of both drawing their authority from a combination of the state and institutional managements. But it is also worth pointing out that Clark also describes how easily formal lines of authority can be subverted. He refers to the common practice within many central and eastern European countries of state authority being 'infiltrated' by senior professors from the local (capital city) university. The present author fondly recalls a dinner in Sofia, the capital city of Bulgaria, with the then Deputy Minister for Higher Education in the Bulgarian Government along with her two immediate predecessors, where the main topic of conversation was the difficulty of combining the duties of Deputy Minister with one's ongoing teaching and research commitments at Sofia University!

The point is perhaps central to Clark's and other analyses of academic organisations: the pervasiveness of compliance and subversion in academics' dealings with authority. Interesting questions posed by Clark's analytic model concern whether today's greater 'managerialism' and controls exercised within the academy successfully overthrow centuries of subversive tradition. Clark's preferences are clear:

We need... administrative doctrines and broader ideologies that tell officials they are doing alright when the system as a whole looks a mess, nearly everyone in the system feels powerless, and no one can clearly identify who is doing what to whom. (Clark 1983, 273)

\section{Key issues facing academia in 1983}

Moving on from Clark's analytic models to the substantive issues facing higher education at the time of his writing, six questions are posed: (i) What determines access? (ii) How can general education be supported? (iii) Can higher education be further 'democratised'? (iv) Can the integration of teaching and research be maintained in mass higher education? ( $v$ ) In a time of expanding state power, what is happening to institutional autonomy? (vi) Is 'graduate unemployment' inevitable?

With the benefits of hindsight, one can note how issues come and go. But the above list still strikes many chords and overlaps considerably with contemporary debates, both within the UK and elsewhere.

Clark's list of issues is complemented by a list of key values: of social justice, competence, liberty and loyalty. These are values possessed in different combinations and to different degrees by academic workers, governments and other stakeholders. Clark saw the tensions between them, observing wryly that 'any sensible administrator asked to confront directly and to reconcile these four orientations would undoubtedly seek other employment' (Clark 1983, 23I).

Clark saw ambiguity, disorder and conflict as endemic and directly arising out of the tensions between these values. Looking at the list today, one wonders about the continuing salience of 
values of liberty and loyalty and their possible replacement by words such as competitiveness and entrepreneurship.

As indicated earlier, as well as presenting an analytical framework and a set of substantive issues to be addressed, Clark was not reticent in presenting his own ideas of 'what should be done'.

His overarching preferences were set out under four headings: the division of power; the support of variety; the legitimation of disorder; and the uniqueness of higher education. On the latter, he comments that 'it does not make much sense to evaluate business firms according to how much they act like universities... Neither does it make any sense to do the reverse' (Clark 1983, 25I).

In the English-speaking world at least, it is difficult to escape the conclusion that many key actors, both inside and outside higher education, do in fact expect universities to behave like businesses. As business terminologies, values and consultants increasingly invade the corridors of universities, one wonders how far the older claims for higher education's uniqueness and exceptionalism remain relevant and valid.

As well as these overarching value preferences, Clark also sets out a series of 'ideas' for higher education to adopt. While it is not clear how far these ideas derive from the application of Clark's analytic model or from his own values and preferences, many of them are still highly relevant to contemporary debates about how we should organise our universities and higher education systems. Here are just six of Clark's key ideas from 1983:

- Conflict among basic values in higher education is accommodated better by diverse than by simple structures. (254)

- In the service of competence, the most crucial form of diversification in modern advanced systems is vertical status differentiation among institutions. (255) (In part justified by Clark on the grounds that 'status inequality makes for hope' (256).)

- In the service of liberty, the most essential form of diversification is the creation and maintenance of different sectors and subsectors. (257)

- Justice in higher education is most effectively implemented if it is institutionally disaggregated instead of applied blanket fashion across a system. (259)

- State control of higher education works better by long-run rewards than by short-run sanctions. (260)

- Value ambivalence in higher education is mirrored in structural ambivalence. (26I)

It is possible to see in this list some of the features of US higher education then and now and of the interests of the elite institutions of the system to which Clark belonged. For all that, they are interesting and far-sighted points concerning important choices that have to be made about the shape and form of higher education systems and the steering mechanisms which guide them.

\section{Key issues facing academia in 2010}

Starting from a similar proposition to that adopted by Burton Clark in 1983, that is higher education should be examined within a wider context of social science research, the European Science Foundation (ESF) recently supported a 'Forward Look' activity to look at higher education and to derive a future research agenda for it. As part of the Forward look, a series of working papers were commissioned on different higher education themes and were discussed and subsequently revised at a series of cross-national workshops during 2007/8 at different European venues. The themes were: (i) higher education and the needs of the knowledge society; (ii) higher education and the achievement (or prevention) of equity and social justice; (iii) higher education and its communities: interconnections and interdependencies; (iv) steering and governance of higher 
education; ( $v$ ) differentiation and diversity of institutional forms and professional roles. If we compare the themes with the main lines of enquiry of The Higher Education System, we can note rather greater concerns with externalities - especially in themes (i) to (iii) - with the overlaps more concentrated on themes (iv) and (v) dealing respectively with steering mechanisms and institutional forms.

The final report of the ESF project (Brennan et al. 2008) provides a synthesis of the project's findings under the headings of (i) changing socio-political contexts; (ii) mechanisms of interaction between society and higher education; (iii) the implications for higher education; (iv) the impact of higher education on society; ( $v$ ) methodological issues. Drawing on all of the Forward Look work, the report proposes a research agenda made up of the following questions:

(i) What are the relationships and interconnections between contemporary social and economic changes and transformations and the changes and transformations occurring within higher education institutions and the role of academics?

(ii) How are the changes in the balance of power between higher education's different constituencies and interests impacting upon the nature of higher education's social functions and the manner in which these are discharged?

(iii) Are a growing multifunctionality of higher education and a blurring of its boundaries with other social institutions necessary in order for higher education to have an importance within a 'knowledge society'?

(iv) How do changes in the organisation of higher education institutions relate to changes in intellectual programmes, agendas and advances?

(v) Do different forms of differentiation and inter-institutional diversity result in different relationships between higher education and the larger social and economic worlds of which it is a part?

(vi) To what extent and in what ways do national, regional and local contexts continue to play a decisive role in determining the characteristics of modern higher education systems? What is the role played by various public authorities? How much variation is there in the extent to which universities are internationally connected or integrated and with what consequences?

(vii) How might new forms of comparative research, involving both quantitative and qualitative approaches, be employed in order to achieve a better understanding of the interactions between higher education and society and the different forms these interactions take in different parts of Europe and more widely?

The Forward Look led to the development of a new international programme of comparative research on 'Higher Education and Society' (EUROHESC) with four multinational projects funded to explore some of the above questions.' The purposes of the ESF's and Clark's agendas contain both differences and overlaps. One important difference, of course, is that whereas the ESF was mainly just posing questions in the Forward Look, Clark was simultaneously also seeking to supply answers. But it is also possible to see ways in which key elements of Clark's analytic framework could be used to explore some of the questions posed by the ESF report. In particular, Clark's framing of the different forms of authority to be found across different higher education systems is suggestive of different forms of engagement between universities and the larger social worlds that are indicated in the ESF agenda. And within these different forms of authority and engagement may lie different capabilities of higher education to change and respond to different external circumstances and expectations.

In his own analysis of change, Clark points to the difficulties, if not impossibilities, of achieving it within institutions characterised by differing mixes of order and disorder, control and subversion. In a recent UK study undertaken by the present author on the regional impacts of 
universities, ${ }^{2}$ several external stakeholders noted how 'vice-chancellors could not deliver their universities'. In the same study, a number of vice-chancellors did not deny the charge. Change, where it happens, may be more likely to occur at the level of the basic unit. Clark notes that:

Units can independently prosper or burn out, survive or die - with the latter usually coming about by slow attenuation over a long period of time, turning a once vibrant organism into a mere shell of its former self. (Clark 1983, 187)

Survival or death may be particularly apt notions to apply to UK higher education at the present time. Clark's analysis of change processes in terms of order and disorder and in terms of integration and differentiation remains useful today. But also his emphasis upon the resistances to change embedded in structures and cultures within individual higher education systems will be either reassuring or frightening, according to the reader's interests and values. Institutions do adapt, but they tend to do so in idiosyncratic and unpredictable ways. Again quoting Durkheim, Clark writes:

It is the peculiar internal constitutions of universities that allow them, in Durkheim's phrase, to 'bend and adapt themselves to a whole variety of circumstances and environments' thus producing diversity... and, at the same time, to maintain an appearance of similarity. (Clark 1983, 187)

The 'appearance of similarity' and the reality of difference are among the many key underlying assumptions of Clark's writings.

\section{The higher education system in the twenty-first century}

In the intervening decades since Clark gave us The Higher Education System, we have witnessed in many countries of the world a continued expansion of higher education, increased differentiation - both horizontal and vertical - new forms of relationship between higher education and the state, growing marketisation and consumerism, the effects of globalisation, of the arrival of 'new public management' and a range of different claims for the 'knowledge society' and higher education's place within it. Clark's analysis is an excellent reminder of where our higher education institutions are coming from. But how good is it as a pointer to the future, how to understand it and how to shape it.

Clark's central concepts of knowledge, belief and authority remain essential tools in our attempts to both comprehend and shape the work of universities and other higher education institutions. They are particularly valuable when used to examine the very real differences which exist between both different kinds of universities and different kinds of higher education system. And the recognition that there are very real differences - notwithstanding globalisation effects - between different systems and institutional traditions is something which Clark's continuous use of international comparisons usefully alerts us to.

However, there are differences between now and then, at least in terms of emphasis if not in more fundamental ways. One of these lies in the permeation of boundaries, both within higher education institutions and between them and other social institutions. The boundaries of those once so powerful 'basic units' of higher education organisation are today generally much weaker than when Clark was writing. As noted earlier, internally the 'enterprise' has acquired greater force together with the power and desire to re-write knowledge maps and to pull down knowledge walls, albeit while resurrecting new ones in different locations. And externally, new channels and mechanisms to achieve greater responsiveness and accountability are to be found everywhere, even if resistances remain and outcomes cannot be assured. In achieving many of their functions, today's universities must enter into alliances and partnerships with all sorts of organisations. They may still strive for their autonomy and independence, but their ability to achieve them is rather less, the more so for some types of institutions than others. 
Arguably, higher education's growing importance in modern societies means that its direction and development can no longer be left to the insiders, to the academic tribes and their interests. Consumerism directs more power to the university's students. Managerialism directs more power to the enterprise and its managers, and beyond them to the representatives of the state and other external stakeholders. And the knowledge society points to the need for more collaborations and partnerships with other organisations, collaborations and partnership where the university is no longer the senior or major partner.

The need to add new elements and new emphases to Clark's analysis of nearly 30 years ago does nothing to lessen the enormous value and usefulness of the original. To those who use them, to those who work in them, to those who pay for them, and especially to those who attempt to steer and govern them, Burton Clark's analysis of academic organisation remains an essential tool of both enlightenment and survival.

\section{Notes}

I. 'Higher Education and Social Change' is a EUROCORES programme of the European Science Foundation.

2. 'Higher Education and Regional Transformation: Social and Cultural Perspectives', a research project funded by the Economic and Social Research Council.

\section{Notes on contributor}

John Brennan is Professor of Higher Education Research at the Open University where he is also Director of the Centre for Higher Education Research and Information. He is the author of several books and many articles on higher education's changing relationships with society and has directed many national and international projects which have explored these themes.

\section{References}

Becher, T. 1989. Academic tribes and territories. Buckingham: Open University Press.

Becher, T., and M. Kogan. 1980/1992. Process and structure in higher education. London: Routledge

Brennan, J. 2007. On researching ourselves: The difficult case of autonomy in researching higher education. In Autonomy in social science university research - the view from the UK and Australian universities, ed. C. Kayrooz, G. Akerlind, and M. Tight, 167-82. London: Elsevier.

Brennan, J., J. Enders, C. Musselin, U. Teichler, and C. Musselin. 2008. Higher education looking forward: An agenda for future research. Strasbourg: European Science Foundation.

Clark, B.R. 1983. The higher education system: Academic organization in cross-national perspective. Berkeley and Los Angeles: University of California Press.

Clark, B.R. 1998. Creating entrepreneurial universities: Organisational pathways of transformation. Dordrecht: Springer.

Durkheim, E. 1977. The evolution of educational thought. London: Routledge. 